\title{
Pelatihan E-learning Dan Pembuatan Buku Ajar Digital Bagi Peningkatan Peran Guru Millenial
}

\author{
E-learning Training and Making Digital Textbooks for Increasing The Role of Millenial \\ Teachers
}

\author{
Jajo Firman Raharjo ${ }^{1}$, Nurul Ikhsan Karimah². \\ 1,2, Program Studi Pendidikan Matematika, FKIP, Universitas Swadaya Gunung Jati, Indonesia \\ e-mail: ${ }^{1}$ jajofirmanraharjo@gmail.com , ${ }^{2}$ nikhsank@gmail.com
}

\begin{abstract}
Abstrak
Covid 19 telah memberikan pembelajaran berharga bahwa dibutuhkan kemampuan adaptasi agar dapat menyesuaikan dengan era digitalisasi dan industry 4.0. Bukan semata-mata penguasaan metode daring, namun lebih fundamental terkait penyiapan metode-metode pembelajaran yang suitable disajikan secara daring. Implementasi dari penyiapan metode-metode pembelajaran yang suitable salah satunya adalah kecakapan guru dalam mengembangakan literasi digital dalam mendukung pembelajaran berbasis daring, seperti kemampuan menerapkan pembelajaran daring, membuat konten pembelajaran daring dan mengimplementasikan dalam kelas virtual sesuai kemampuan didaktis dan pedagogis guru. 3D Pageflip Professional adalah suatu software yang dapat dimanfaatkan untuk membuat bahan ajar berbentuk e-book digital dengan efek 3D. Software ini mampu mengubah bahan ajar berbentuk PDF, Open Office, Ms. Office, gambar menjadi e-book 3D Flash yang menakjubkan dengan berbagai format. Pengabdian ini adalah pelatihan dan pengembangan media pembelajaran berupa modul berbasis multimedia dan menggambarkan cara membuat modul berbasis multimedia menggunakan 3D PageFlip Professional dengan tampilan akhir yang dapat diakses melalui computer pada guru-guru di SMA Negeri 1 Losari Kabupaten Cirebon.Hasil dari kegiatan ini adalah Best Practice pembelajaran dalam jaringan (daring) menggunakan berbagam macam e-learning. dan praktik pembuatan buku ajar digital dengan aplikasi $3 D$ Pageflip untuk meningkatkan kompetensi Subject Content Knowledge dan Pedagogic;
\end{abstract}

Kata kunci: Pelatihan E-learning, Buku Ajar Digital, Peran Guru Millenial, Best Practise

\begin{abstract}
Covid 19 has provided valuable lessons that adaptability is needed in order to adapt to the era of digitalization and industry 4.0. Not only mastery of online methods, but more fundamentally related to the preparation of suitable learning methods presented online. One of the implementation of the preparation of suitable learning methods is the ability of teachers to develop digital literacy in supporting online-based learning, such as the ability to apply online learning, create online learning content and implement it in virtual classrooms according to the teacher's didactic and pedagogical abilities. 3D Pageflip Professional is a software that can be used to create digital e-book teaching materials with $3 D$ effects. This software is capable of converting teaching materials in the form of PDF, Open Office, Ms. Office, images into stunning $3 D$ Flash e-books with various formats. This service is a training and development of learning media in the form of multimedia-based modules and describes how to make multimedia-based modules using $3 D$ PageFlip Professional with a final display that can be accessed via computer for teachers at SMA Negeri 1 Losari, Cirebon Regency. The result of this activity is Best Practice online learning uses a variety of elearning. and practice of making digital textbooks with the $3 D$ Pageflip application to improve Subject Content Knowledge and Pedagogic competences;
\end{abstract}

Keywords: E-learning Training, Digital Textbook, The Role of Millenial Teachers, and Best Practice.

\section{PENDAHULUAN}

Covid 19 telah memberikan pembelajaran berharga bahwa dibutuhkan kemampuan adaptasi agar dapat menyesuaikan dengan era digitalisasi dan industry 4.0. Bukan semata-mata penguasaan metode daring, namun lebih fundamental terkait penyiapan metode-metode pembelajaran yang suitable disajikan secara daring. Kegiatan akademik yang dilakukan secara online, secara bertahan merubah dari konvensional kampus mengarah ke smart campus mengarah

Submitted: Januari 2021, Accepted: Februari 2021, Published: Februari 2021

ISSN 2746-6345 (media online) 
ke digital campus dan cyber campus. Implementasi dari penyiapan metode-metode pembelajaran yang suitable salah satunya adalah kecakapan guru dalam mengembangakan literasi digital dalam mendukung pembelajaran berbasis daring, seperti kemampuan menerapkan pembelajaran daring, membuat konten pembelajaran daring dan mengimplementasikan dalam kelas virtual sesuai kemampuan didaktis dan pedagogis dosen. Salah satunya contohnya adalah digitalisasi bahan ajar yang diimplementasikan dalam pembelajaran daring.

Media pembelajaran harus dipersiapkan oleh guru sekreatif mungkin? Kita lihat pengertian media pembelajaran menurut (Afandi, 2017) mendefinisikan Istilah media berasal dari bahasa latin, yakni medius yang secara harfiah berarti 'tengah', 'pengantar' atau 'perantara'. Dalam bahasa Arab media disebut 'wasail' bentuk jama' dari 'wasilah' yakni sinonim alwasth yang artinya juga 'tengah' itu sendiri berarti berada diantara dua sisi, maka disebut juga sebagai 'perantara' berada diantara dua sisi, maka disebut juga sebagai 'perantara'(Media et al., 2019). Karena posisinya berada ditengah ia bisa juga disebut sebagai pengantar atau penghubung, yakni mengantarkan atau menghubungkan atau menyalurkan sesuatu hal dari satu sisi ke sisi lainnya. Selain itu, (Ilyasa Aghni, 2018) menjelaskan bahwa media apabila dipahami secara garis besar adalah manusia, materi, atau kejadian yang membangun kondisi yang membuat siswa memperoleh pengetahuan, keterampilan, atau sikap. Berbagai pengalaman yang diperoleh siswa merupakan suatu dasar bagi siswa untuk mengembangkan media atau alat bantu yang disediakan oleh guru dalam proses memahami pelajaran dan memecahkannya(Darmawati \& Julianto, 2018).

$3 D$ Pageflip Professional adalah suatu software yang dapat dimanfaatkan untuk membuat bahan ajar berbentuk e-book digital dengan efek 3D(Raihan \& Ahmadi, 2018). Software ini mampu mengubah bahan ajar berbentuk PDF, Open Office, Ms.Office, gambar menjadi e-book 3D Flash yang menakjubkan dengan berbagai format. Pengabdian ini adalah pelatihan dan pengembangan media pembelajaran berupa modul berbasis multimedia dan menggambarkan cara membuat modul berbasis multimedia menggunakan 3D PageFlip Professional dengan tampilan akhir yang dapat diakses melalui komputer. Dalam merancang modul berbasis multimedia menggunakan 3D PageFlip Professional membutuhkan modul dalam format PDF sebagai dasar modul berbasis multimedia. Peningkatan profesionalisme guru sudah sewajarnya dilakukan, tidak hanya oleh pemerintah tapi dari diri guru itu sendiri juga harus punya kemauan dan upaya yang keras untuk bisa lebih profesional sehingga tujuan pendidikan nasional dapat tercapai seperti yang tercantum dalam Undang-undang Guru dan Dosen.

Kendala yang menjadi tantangan bagi mitra adalah bagaimana mengembangkan Best Practise dan Role Model untuk meningkatkan kualitas pembelajaran dalam masa pandemi, sehingga tercipta kualitas siswa yang unggul salah satunya adalah kemampuan literasi digital yang mengharuskan guru kreatif dalam mengembangkan pembelajaran yang dianggap masih kurang. Kegiatan pelatihan biasanya terkenda pada masalah waktu dan biaya. Masih banyak ditemukan bahwa guru-guru masih belum menyadari dan mengoptimalkan pentingnya mengembangkan profesionalisme dalam kegiatan-kegiatan ilmiah. Mereka menganggap bahwa setiap kegiatan tentunya memerlukan yang namanya biaya dan waktu yang cukup ditengahtengah kesibukan sebagai seorang guru. Sehingga optimalisasi kegiatan berkelanjutan melalui pengembangan lesson study untuk membentuk komunitas belajar bisa dilakukan. Selain itu, permasalahan yang dirumuskan antara lain:

1. Bagaimana merancang pembelajaran dalam jaringan (daring) menggunakan berbagam macam e-learning dan praktik pembuatan buku ajar digital dengan aplikasi 3D Pageflip untuk meningkatkan peran guru millenial.

2. Bagaimana Bahan ajar digital dengan aplikasi 3D Pageflip yang dibuat dapat diimplementasikan pada pembelajaran e-learning untuk meningkatkan peran guru millenial.

Tujuan Pengabdian ini adalah untuk mengembangkan bagaimana meningkatkan pengetahuan/pemahaman kepada guru dalam mengembangkan

1. Best Practise bagaimana merancang pembelajaran dalam jaringan (daring) menggunakan berbagam macam e-learning dan praktik pembuatan buku ajar digital dengan aplikasi 3D Pageflip untuk meningkatkan peran guru millenial. 
2. Artikel yang disusun oleh Tim Pengusul Program PPM dan dipublikasikan dalam jurnal pengabdian

3. Bahan ajar digital dengan aplikasi 3D Pageflip dengan pendekatan saintifik (Buku Ajar matematika saintific) untuk meningkatkan peran guru millenial.

Dalam kegiatan pengabdian ini, yang menjadi khalayak sasaran adalah guru-guru SMA Negeri 1 Losari Kabupaten Cirebon, yang mempunyai kemauan dan kemampuan untuk dilatih dalam penggunaan atau pembuatan produk berupa buku ajar yang disesuaikan dengan pendekatan saintific. Solusi yang ditawarkan dari permasalahan diatas adalah Kegiatan pelatihan, penyuluhan dan pendampingan bagaimana merancang pembelajaran dalam jaringan (daring) menggunakan berbagam macam e-learning dan praktik pembuatan buku ajar digital dengan aplikasi 3D Pageflip untuk meningkatkan peran guru millenial. Dilihat dari profesi dan pengalamannya, guru-guru memiliki potensi, pengetahuan dan kemampuan untuk membuat dan menggunakan buku ajar yang disesuaikan dengan pendekatan saintific. Dilihat dari lingkungannya sekolah memiliki sumber dan media belajar yang melimpah untuk dapat terus meningkatkan profesionalitas guruguru.

Dalam kajian ini, Pelatihan pembuatan buku ajar digital akan disesuaikan dengan karakteristik materi yang pembelajarannya dilakukan melalui e-learning dengan berbantuan buku digital yang dikembangkan dengan Aplikasi 3D Pageflipe melalui kelas virtual. 3D PageFlip merupakan software pembuat E-Book atau digital book, E-Katalog, E-Brosur dengan halaman balik efek 3D dan berputar efek dalam beberapa menit(Prasetyo, 2018). 3D PageFlip adalah software flash Flipbook sempurna untuk mengubah file PDF, Word, PowerPoint, dan Excel ke bentuk flipbooks menjadi majalah digital 3D yang realistis(Jafnihirda et al., 2019). Dengan 3D PageFlip, Anda dapat membuat realistis majalah 3D yang bagus dan interaktif, E-katalog, ebrosur, e-Book dengan membalik-balik halaman surat kabar atau apa saja dimanapun tanpa keterampilan pengetahuan atau pemrograman Flash / HTML dalam waktu singkat. Dan Anda mendapat output 3D Digital Brosur online, offline (pada PC Anda, iPad, dll), bahkan membakarnya ke CD / DVD atau menggunakannya dengan perangkat penyimpanan USB.

Pembinaan dan pengembangan profesi guru hanya dapat dilakukan secara efektif jika berbasis pada pemetaan kompetensi guru(Guru et al., 2020). Pemetaan itu berupa kompetensi pedagogik dan professional (Content Knowledge), sebagai dasar program Pengembangan Keprofesian Berkelanjutan (PKB) dan bagian dari proses Penilaian Kinerja dan Kompetensi (PKK). Untuk membangun eksistensi dan martabat sebuah profesi tentunya diperlukan mutu atau kualitas para anggota yang tergabung dalam profesi tersebut. Mutu atau kualitas diperoleh dari upaya pengembangan keprofesian berkelanjutan dan pengendalian yang dilaksanakan secara terus menerus dan tersistem yang dapat berupa pelatihan professional maupun forum ilmiah. Tidak hanya guru harus berupaya mengembangkan keprofesiannya tetapai pula diperlukan upaya pengendalian melalui pengujian dan pengukuran. Profesi guru akan bermutu jika secara terusmenerus dilakukan pengujian dan pengukuran terhadap kompetensi guru melalui uji kompetensi guru.

Kompetensi Content Knowledge adalah kemampuan untuk menguasai materi pembelajaran secara luas dan menyeluruh, yang tentunya dapat memungkinkan mendorong siswanya agar tercapai kompetensi lulusannya sesuai dengan standar yang ditetapkan. Adapun indicator dari kompetensi ini antara lain:

a) Menguasai substansi bidang studi dan metodologi keilmuan.

b) Menguasai struktur dan materi kurikulum dari bidang yang diajarkan.

c) Menguasai dan memanfaatkan teknologi informasi dalam pembelajaran.

d) Mengorganisasi materi kurikulum bidang studi yang diajarkan.

e) Meningkatkan kualitas pembelajaran melalui penelitian baik penelitian tindakan kelas maupun metodelogi penelitian lainnya. 
Dalam kaitannya dengan kompetensi ini maka seorang guru dapat berperan sebagai fasilitator dalam pembelajaran. Sebagai fasilitator guru berperan penting dalam membantu siswanya dalam belajar, guru bukan satu-satunya sebagai sumber belajar tetapi berperan sebagai salah satu sumber belajar, fasilitator adalah dimensi upaya pemberdayaan peserta didik agar berkembang secara optimal dalam proses belajarnya.

Kompetensi Pedagogik adalah kemampuan guru dalam mengelola pembelajaran yang dilakukan pada peserta didik(Andini \& Supardi, 2018). Adapun aspek pada kompetensi pedagogic antara lain:

a) Menguasai karakteristik peserta didik

b) Menguasasi teori belajar dan prinsip-prinsip pembelajaran yang mendidik

c) Pengembangan kurikulum

d) Kegiatan pembelajaran yang mendidik

e) Pengembangan potensi peserta didik

f) Komunikasi dengan peserta didik

g) Penilaian dan Evaluasi

Pentingnya Pelatihan Kompetensi Content Knowledge Dan Pedagogik bagi Guru(Wulandari \& Iriani, 2018)

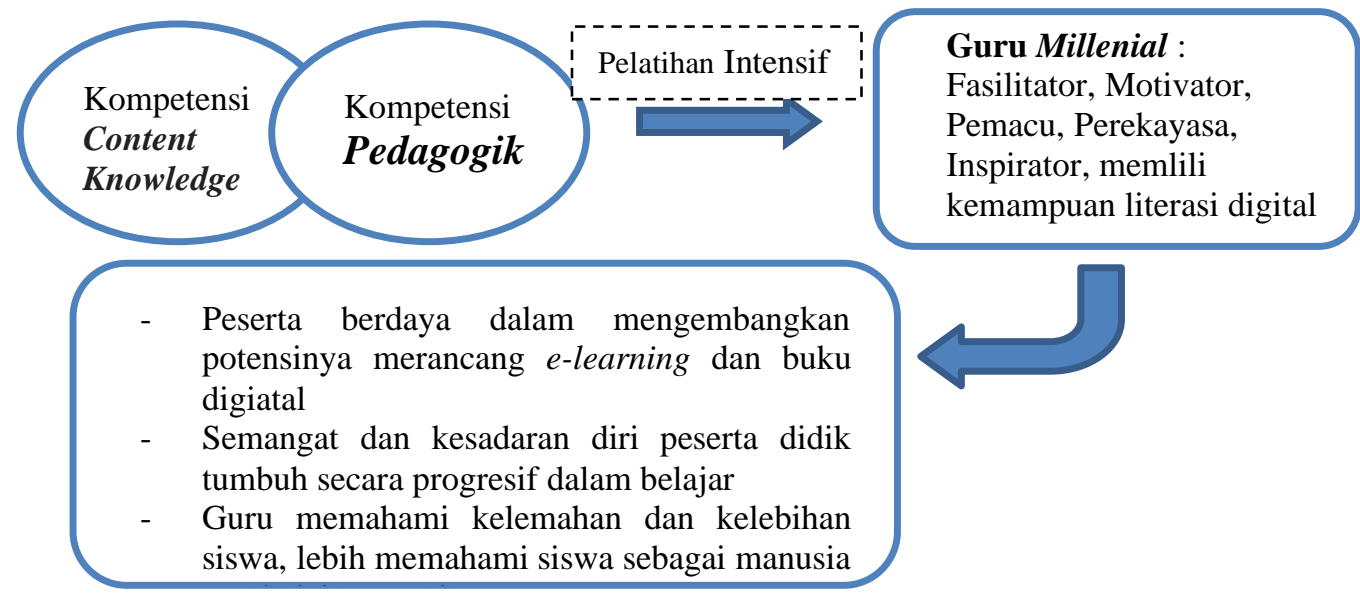

Gambar 1. Content knowledge dan pedagogic guru

Adapun harapan akan hasil dan manfaat kegiatan ini adalah:

1. Dengan adanya pelatihan ini, diharapkan guru bisa merancang Best Practise pembelajaran dalam jaringan (daring) menggunakan berbagam macam e-learning dan

2. Guru dapat melakukan praktik pembuatan buku ajar digital dengan aplikasi 3D Pageflip untuk meningkatkan peran guru millenial.

3. Bahan ajar digital dengan aplikasi 3D Pageflip yang dibuat dapat diimplementasikan pada pembelajaran e-learning untuk meningkatkan peran guru millenial.

\section{METODE PELAKSANAAN}

Metode kegiatan PPM (Pengabdian Pada Masyarakat) ini berupa pelatihan, simulasi dan evaluasi mengembangkan buku ajar digital dengan aplikasi 3D PageFlip Professional kepada guru-guru SMA Negeri 1 Losari Kabupaten Cirebon. Untuk kegiatan pelatihan, materi yang akan dilatih untuk guru-guru yaitu matematika, pedagogic content knowledge, kemudian untuk kegiatan pelatihan berupa pentransformasian buku ajar menjadi buku ajar digital melalui software 3D Pageflip untuk simulasi buku ajar digital dengan pendekatan saintifik (Buku Ajar saintific) untuk meningkatkan pedagogic content knowledge, sedangkan untuk evaluasi dapat menentukan guru-guru yang dinyatakan memenuhi atau lulus dalam simulasi mengembangkan buku ajar digital dengan aplikasi 3D PageFlip Professional dan yang belum lulus. 
Di sini bagi guru yang belum lulus simulasi akan dievaluasi, bagian mana yang masih kurang dan kembali dilakukan pelatihan sehingga guru tersebut dapat lulus simulasi pengembangan buku ajar digital.

Berikut ini adalah tahapan kegiatan PPM yang akan dilakukan:

1. Tahap Persiapan

a) Mensosialisasikan program PPM kepada guru-guru SMA Negeri 1 Losari Kabupaten Cirebon.

b) Mendata peserta, menentukan waktu, jadwal dan tempat untuk menyelenggarakan program PPM.

c) Menyusun bahan/materi pelatihan berupa modul/handout dan media pembelajaran berupa PPT.

d) Menyiapkan Computer Based Design (CBD) sebagai simulasi untuk mengembangkan simulasi mengembangkan buku ajar digital dengan aplikasi 3D PageFlip Professional.

2. Tahap Pelaksanaan Pelatihan dan Pendampingan

Berikut ini dilakukan beberapa tahapan pelatihan dan pendampingan yaitu workshop mengenai pembuatan simulasi mengembangkan buku ajar digital dengan aplikasi 3D PageFlip Professional yang terdiri dari pelatihan, simulasi dan evaluasi meliputi beberapa kegiatan sebagai berikut:

Untuk Pelatihan :

a) Memberikan pelatihan kepada guru-guru mengenai subject knowledge dan matematika sebagai bahan-bahan dalam simulasi mengembangkan buku ajar digital dengan aplikasi $3 D$ PageFlipe Professional secara daring.

b) Memberikan pelatihan kepada guru-guru mengenai software 3D Pageflipe sebagai pelatihan dalam pembuatan buku ajar digital dengan aplikasi 3D PageFlip Professional.

c) Memberikan pelatihan kepada guru-guru mengenai pendekatan saintific sebagai bahanbahan dalam buku ajar digital dengan aplikasi 3D PageFlip Professional.

Kegiatan pelatihan ini dilaksanakan dengan waktu dan tempat yang telah ditentukan.

Untuk Simulasi:

Memberikan simulasi mengembangkan buku ajar digital dengan aplikasi 3D PageFlip Professional dengan sistem CBD (Computer Based Design) sebagai uji coba terhadap guru-guru yang telah mendapatkan materi dari pelatihan sebelumnya. Kegiatan simulasi ini dilaksanakan dengan jadwal dan tempat yang telah ditentukan.

Untuk Evaluasi:

Setelah guru-guru melaksanakan program simulasi buku ajar digital dengan aplikasi $3 D$ PageFlip Professional untuk meningkatkan pedagogic content knowledge, maka tim PPM akan melakukan penilaian dan mendata guru mana saja yang memenuhi dan tidak memenuhi standar dalam mengembangkan buku ajar digital dengan aplikasi 3D PageFlip Professional. Kemudian bagi guru-guru yang belum memenuhi akan dilakukan tes simulasi (dalam hal ini $C B D$ ) secara berkala hingga guru-guru tersebut memenuhi standar yang telah ditentukan. Lebih lanjut akan diadakan evaluasi secara menyeluruh baik dalam pelaksanaan program PPM maupun keberlanjutan dari program PPM setelah dilaksanakan. Alur kegiatan pelatihan dan pendampingan, dapat dipaparkan dalam Gambar 2. . 


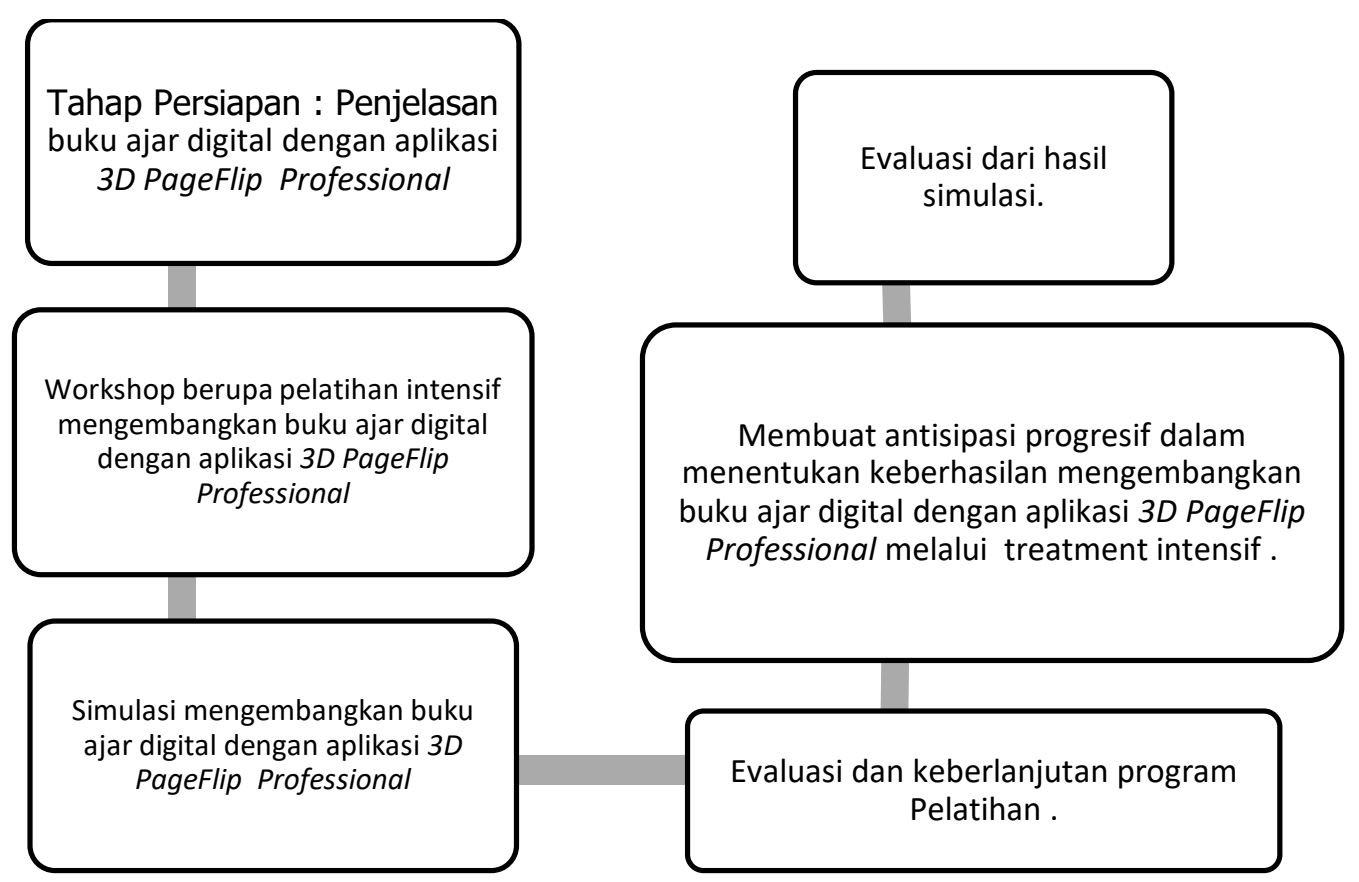

Gambar 2. Alur Pelatihan dan Pendampingan

\section{HASIL DAN PEMBAHASAN}

\section{Hasil dan Pembahasan Pengabdian}

Target Luaran yang dihasilkan kegiatan PPM adalah Pelatihan mengembangkan buku ajar matematika dengan pendekatan saintifik (Buku Ajar matematika saintific) Bagi Guru-Guru di Kabupaten Cirebon adalah guru di Kabupaten Cirebon memiliki pemahaman dan kemampuan yang cukup terkait bagaimana merancang pembelajaran dalam jaringan (daring) menggunakan berbagam macam e-learning dan praktik pembuatan buku ajar digital dengan aplikasi 3D Pageflip untuk meningkatkan kompetensi Subject Content Knowledge dan Pedagogical. Adapun hasil pengabdian adalah sesuai tebel berikut:

Tabel 1. Alat Keberhasilan Program Pelatihan Pendesainan mendesain pembelajaran dalam jaringan (daring) menggunakan berbagam macam e-learning dan praktik pembuatan buku ajar digital dengan

\begin{tabular}{|l|l|l|l|}
\hline No & Bidang yang diukur pada PKM & Hasil & Dokumentasi \\
\hline 1. & Secara Online Guru pelatihan dilaksanakan & $85 \%$ \\
agar guru memahami kualitas isi buku ajar, \\
yang meliputi: \\
Pembelajaran dalam jaringan (daring) \\
menggunakan berbagam macam e- \\
learning harus sesuai dengan standar isi, \\
standar proses dan standar penilaian sesuai \\
kurikulum yang berlaku yaitu kurikulum \\
2013. \\
Pembelajaran dalam jaringan (daring) \\
menggunakan berbagam macam e- \\
learning. Menantang dalam hal ini adalah \\
Pembelajaran dalam jaringan (daring) \\
menggunakan berbagam macam e-
\end{tabular}




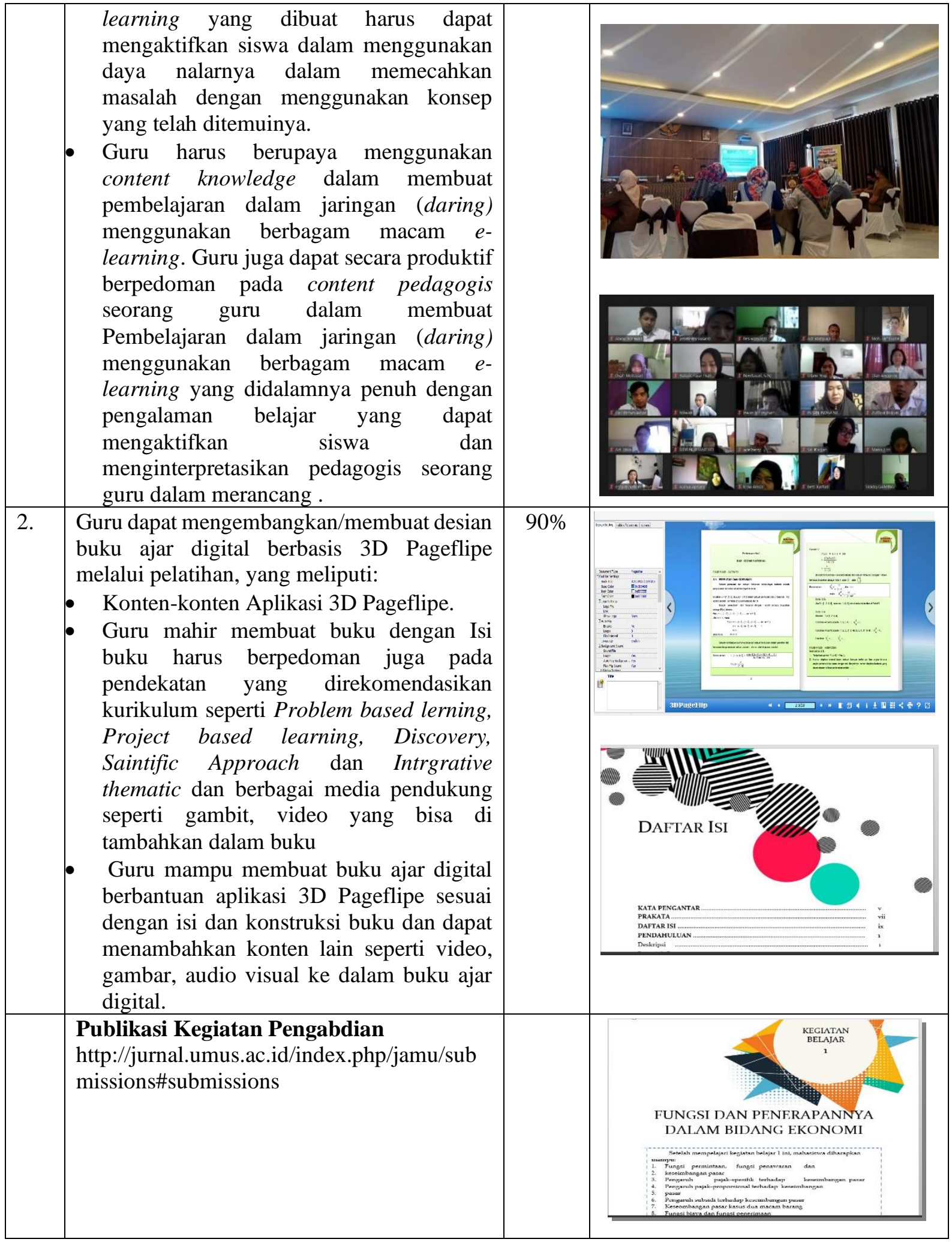

\section{Keberlanjutan Program}

Keberlanjutan program pengabdian ini adalah terealisasikannya hasil pengabdian berupa Best Practice bagaimana merancang pembelajaran dalam jaringan (daring) menggunakan berbagai macam e-learning dan praktik pembuatan buku ajar digital dengan aplikasi 3D Pageflip untuk 
meningkatkan kompetensi peran guru millennial diimplementasikan pada pengabdian selanjutnya yaitu pelatihan lesson study dan implementasi hasil yang sudah diperoleh tersebut.

\section{KESIMPULAN}

Berdasarkan hasil dan tahapan pelatihan yang dilakukan, maka produk pengabdian ini dapat disimpulkan bahwa Best Practise bagaimana merancang pembelajaran dalam jaringan (daring) menggunakan berbagam macam e-learning dan praktik pembuatan buku ajar digital dengan aplikasi 3D Pageflip untuk meningkatkan peran guru millennial. Artikel yang disusun oleh Tim Pengusul Program PPM dan dipublikasikan dalam jurnal pengabdian. Bahan ajar digital dengan aplikasi 3D Pageflip dengan pendekatan saintifik (Buku Ajar matematika saintific) untuk meningkatkan kreativitas content knowledge dan content pedagogic.

\section{UCAPAN TERIMAKASIH}

Ucapan terimakasih kami sampaikan kepada Lembaga Pengabdian Masyarakat (LPM) Universitas Swadaya Gunung Jati (UGJ), yang telah mendanai program ini melalui Hibah Internal PKM UGJ 2020/2021. Kami juga memberikan apresiasi kepada peserta mitra, para dosen pengabdian kepada masyarakat, mahasiswa yang terlibat dan pihak lain yang berkontribusi. Semoga keberlanjutan program pengabdian ini bisa terealisasikan pada pengabdian selanjutnya yaitu pelatihan lesson study dengan best practice yang sudah diperoleh pada pengabdian ini dan implementasi buku ajar digital yang telah di buat.

\section{DAFTAR PUSTAKA}

Afandi, A. (2017). Pembelajaran Langsung Dengan Menggunakan Media Flash Untuk Siswa SMP. Jurnal Sistem \& Teknologi Informasi Indonesia, 2(1), 51-57. https://doi.org/https://doi.org/10.32528/justindo.v2i1.1040

Andini, D. M., \& Supardi, E. (2018). Kompetensi Pedagogik Guru Terhadap Efektivitas Pembelajaran Dengan Variabel Kontrol Latar Belakang Pendidikan Guru. Jurnal Pendidikan Manajemen Perkantoran, 3(1), 148. https://doi.org/10.17509/jpm.v3i1.9450

Darmawati, E., \& Julianto, J. (2018). Meningkatkan Pemahaman Siswa Dalam Konteks Sastra Dongeng Anak Dengan Media Boneka Tangan Di Sekolah Dasar. Edustream, 2(2).

Guru, U. K., Guru, P. K., Guru, S., Jenderal, S., Serikat, F., \& Indonesia, G. (2020). Program Penilaian Kinerja Guru dan Uji Kompetensi Guru dalam Meningkatkan Prestasi Kerja Guru. Ijemar, 4(1). https://doi.org/http://dx.doi.org/10.4321/ijemar.v4i1.4384

Ilyasa Aghni, R. (2018). Fungsi dan Jenis Media Pembelajaran Dalam Pembelajaran Akuntansi. Jurnal Pendidikan Akuntansi Indonesia, XVI(1). https://doi.org/https://doi.org/10.21831/jpai.v16i1.20173

Jafnihirda, L., Diani, \& Rini Sefriani. (2019). Pengembangan Modul Pembelajaran Desain Grafis Berbasis 3D Pageflip Profesional. Jurnal Pendidikan Teknologi Informasi, 6(1), 45-54. https://doi.org/https://doi.org/10.29165/pti.v6i1.157

Media, P., Kamal, K., Kosakata, P., \& Arab, B. (2019). Pengembangan Media Kartu Kamal dalam Penguasaan Kosakata Bahasa Arab. Al-Irfan, 2(2), 117-132. https://doi.org/https://doi.org/10.36835/al-irfan.v2i2.3588

Prasetyo, A. (2018). Digitalisasi Bagi Pustakawan Guna Penyelamatan Naskah Kuno Di $\begin{array}{lllll}\text { Perpustakaan Wilayah Surakarta. } & \text { Abdi }\end{array}$ https://doi.org/https://doi.org/10.33153/abdiseni.v9i1.2443

Raihan, S., \& Ahmadi, F. (2018). Development of Scientific Learning E-Book Using 3D Pageflip Professional Program. Innovative Journal of Curriculum and Educational Technology, 7(1), 7-14. https://doi.org/10.15294/IJCET.V7I1.24793

Wulandari, M., \& Iriani, A. (2018). Pengembangan Modul Pelatihan Pedagogical Content 
Knowledge (PCK) Dalam Meningkatkan Kompetensi Profesional dan Kompetensi

Pedagogik Guru Matematika SMP. Kelola, 5(2), 177-189.

https://doi.org/https://doi.org/10.24246/j.jk.2018.v5.i2.p177-189 